\title{
Promoting sustainable travel behaviour through the use of smartphone applications: A review and development of a conceptual model
}

\author{
Alfred Andersson $^{\mathrm{a}, *}$, Lena Winslott Hiselius ${ }^{\mathrm{a}}$, Emeli Adell ${ }^{\mathrm{b}}$ \\ ${ }^{a}$ Lund University, Department of Technology and Society, P.O Box 118, SE-221 00 Lund, Sweden \\ b Trivector Traffic, Åldermansgatan 13, SE-222764 Lund, Sweden
}

\section{A R T I C L E I N F O}

\section{Keywords:}

Travel behaviour

ICT

Smartphone applications

Behaviour change

Sustainable mobility

\begin{abstract}
A B S T R A C T
The negative effects of transport in terms of pollution, congestion and climate change has urged the need for higher shares of cleaner and more efficient modes of transport, especially in urban settings. While new technology can solve some of these issues, behaviour changes has also been identified as an important factor to achieve a modal shift from cars to walking, cycling or public transport. This study investigates how ICT has been used to influence behaviour change and synthesizes key aspects into a conceptual model for creating a behaviour change support system (BCSS) for smartphone applications. A literature review concerning behaviour change and ICT in the fields of transport, health, energy and climate was conducted to gather empirical evidence which forms the foundation of the conceptual model. The empirical findings were tested and verified against a theoretical framework consisted of The Transtheoretical Model, Theory of Planned Behaviour, Diffusion of Innovations and the concept of Gamification. The results suggest that customization to the user, relevant and contextualised information and feedback, commitment, and appealing design are important aspects when influencing users to behaviour change through smartphone applications. The conceptual model provides further knowledge of key aspects to consider when developing persuasive tools that aims to encourage more sustainable modes of transport.
\end{abstract}

\section{Introduction}

The global transport sector accounts for 23 percent of $\mathrm{CO}^{2}$ emissions from fossil fuels, and is the sector that contributes most to global warming after electricity and heat production (IEA, 2016). While measures such as energy efficiency, higher incorporation of renewables in the fuel mix and increased production of renewable energy have led to a slower rate of growth of electricity and heat generation emissions, measures to reduce $\mathrm{CO}^{2}$ emissions from the transport sector have not been as effective. Since 1990, global emissions from transport have increased by 71 percent (IEA, 2016).

For Sweden, conversion to a low-carbon energy system has accelerated faster in relation to the rest of the world, thanks to good resources in water and nuclear power, as well as the introduction of district heating instead of oil-based heating to housing. The industry mainly uses biofuels and electricity, however, energy use in transport is still dominated by petroleum and aviation fuel products (Sweden Energy Agency, 2015). Of Sweden's total emissions, transport constitutes one third, of which road traffic accounts for 93 per cent (Sweden Energy Agency, 2015; Environmental Protection Agency, 2016).
At the beginning of 2017, the government presented a proposal for a new climate law, aiming to reduce emissions by 85 percent by 2045 in Sweden, compared with 1990 levels. They also proposed to set a target that emissions from domestic traffic should have decreased by 70 percent by 2030, compared to 2010 levels (Government Offices of Sweden, 2017).

Research has shown that technology, innovation and economic factors alone will not suffice to achieve the climate and environmental objectives set for the transport sector (Nilsson et al., 2013). Sustainable development also requires changes in our behaviour and a development in which car travel decreases (Hiselius and Rosqvist, 2016). According to Anable et al. (2006) there is often a gap between individuals' concerns of climate change and the actual travel behaviour that is performed. It does not, therefore, need to be inadequate knowledge of climate change which is the main problem, but rather how it is translated into practice when choosing modes of transport.

To deal with the inefficient use of transport capacity, Transport Demand Management (TDM) emerged as a concept for restricting access for car traffic and reallocating space in favour for walking, cycling and public transport (Banister, 2011). From this, a similar approach

\footnotetext{
* Corresponding author.

E-mail address: alfred.andersson@tft.lth.se (A. Andersson).
} 
referred to as Mobility Management (MM) has become an increasingly common tool, especially in Europe, in the past 20 years to achieve different transport goals (Litman, 2010). It is a concept for encouraging sustainable transport and managing the demand for car journeys by changing travellers' attitudes and behaviours (Van Acker, Van Cauwenberge and Witlox, 2013). Mobility Management is often referred to as soft actions as the concept rarely includes, however complements, infrastructure solutions and thus focusing on information campaigns, price mechanisms and policies (Litman, 2010).

As digitization begins to influence more community functions, new opportunities emerges for what information and communication technology (ICT), can be used for. A relatively new area is the use of smartphones as a platform for performing Mobility Management actions and influence travel behaviours (Semanjski et al., 2016). A number of studies have investigated ICT and collection of travel data (Wells et al., 2014; Gerike et al., 2016; Semanjski and Gautama, 2016) and some have also evaluated its potential for behaviour change and a tool for promoting sustainable modes of transport (Parvaneh et al., 2014; Poslad et al., 2015; Castellanos, 2016).

Earlier research on Mobility Management often includes behavioural and attitudinal theories (see for example Anable et al., 2006) to answer questions related to the attitude-behaviour gap, where consumers express concerns about environmental issues but fail to translate this into sustainable actions (Anable et al., 2006). A range of different techniques to induce voluntary travel behaviour change has also been developed over the years, such as personalized travel plans (PTP), individualized marketing schemes and organisational travel plans, to mention a few (see Cairns et al., (2008) for an ample review). While the intentions for this study is similar to those investigating how to optimize Mobility Management campaigns, it also aims to expand the knowledge on how to further influence mobility behaviour through smartphone applications, with support in theory. This could be described as an integrated four-step procedure, which includes adopting, shaping, changing and keeping sustainable travel behaviours with assistance of app-technology. This approach offers new possibilities as well as new challenges. By combining behavioural change techniques (BCTs) (Abraham and Michie, 2008) and ICT, research can start experimenting with the opportunities to gamify data and visualize messages differently to appeal to the user. However, fundamental but equally important challenges exists such as getting the targeted population to actually use the application in question. This extended approach demands for a wider scope of theories to be used, certainly behavioural change theories but also theories linked to gaming and adoption of new technologies.

In a recent review of persuasive technologies to promote sustainable mobility, also called behaviour change support systems (BCSS) (Oinaskukkonen, 2010), Sunio and Schmöcker (2017) concludes that too little effort is given on grounding BCSSs in explicit behavioural change theory. Developing a successful BCSS depends not only on the creative and appropriate implementation of the behaviour change techniques, but also on explicitly grounding it on established theoretical constructs from behavioural theories (Arnott et al., 2014). Support for this suggestion can also be found in a significant meta-analysis by (Webb et al., 2010), who argues that a thoroughly rooted BCSS in theoretical foundation is positively correlated with its effectiveness. The potential for smartphone applications as carriers of behaviour change messages should, we argue, not be stalled by ignoring the underlying mechanisms of behaviour change developed from theory.

To the best of our knowledge, so far, the only BCSS grounded in behavioural theory is one called Quantified Traveller (Jariyasunant et al., 2015) which is based on Theory of Planned Behaviour (Ajzen, 1991). Although highly influential in the field of travel behaviour, TPB has been criticized for disregarding the time dimension of behaviour change, which is the mere foundation of other behaviour change theories, like The Transtheoretical Model (Prochaska and DiClemente, 1982). In TTM, change is defined as an incremental, gradual and dynamic process, involving progress through a series of stages. It has been argued that a combination of continuous models and stage models, such as TPB and TTM, can help to explain the process of behaviour change (Forward, 2014). For this purpose, we used a theoretical framework consisting of both Theory of Planned Behaviour and The Transtheoretical Model but also Diffusion of Innovations (Rogers, 1995) and the concept of Gamification (Deterding et al., 2011) to review the content of previous research on behaviour change and ICT and draw conclusions about best practices for developing a BCSS.

There are currently expectations that ICT could be a useful tool for influencing travel behaviours (Brazil and Caulfield, 2013) and earlier research has asserted future platforms for persuasion and behaviour change to be mobile (Fogg and Eckles, 2007). However, there is a lack of research exploring these new platforms for behaviour change in the light of actual behaviour change theory, as pointed out by Klein et al. (2014) as well as Sunio and Schmöcker (2017). It is this knowledge gap in the research that this study seeks to investigate. The authors of this study has conducted a review of previous research on behaviour change and ICT. Apart from providing an overview of one particular field, the rationale for writing a literature review paper is also to add value (Wee and Banister, 2016) which in this study is performed through applying theories on research findings as well as synthesize the results into a conceptual model.

\subsection{Purpose and research questions}

The purpose of the study is to investigate how behavioural change techniques can be implemented in smartphone applications to encourage sustainable travel behaviours. This by (1) examine conclusions from previous research in which the combination of behavioural change techniques and ICT has been studied in the field of transport as well as in other areas, and (2) using a theoretical framework consisting of The Transtheoretical Model, the Theory of Planned Behaviour, Diffusion of Innovations as well as the concept of Gamification, to analyse empirical findings and thus increase the knowledge of how behaviour change support system (BCSS) could be improved.

The aim is to provide knowledge of key aspects to consider when combining behaviour change techniques with ICT and to develop a conceptual model that highlights these aspects, grounded in previous research and theory.

\section{Theory}

To analyse the results extracted from the literature review we applied the theoretical framework on the stages of adopting, shaping, changing and keeping sustainable travel behaviours with the use of smartphone applications. We made the assumption that these four stages are vital to consider when developing a BCSS, from adopting the tool to recognizing the new behaviour as a habit. Although this division makes for better theoretical overview, in reality we consider them very much integrated, both in practice and in theory. However, as a theoretical overview our approach can be described as in Fig. 1. By taking this approach we seek to get a holistic, theoretical perspective on developing a BCSS, as requested in previous research (Klein et al., 2014; Sunio and Schmöcker, 2017). With "Adopting" we refer to the crucial process in which the user utilize the smartphone application and engage with its content. Although many people today interact with smartphones (in Sweden, 81 percent have access to a smartphone and 65 percent use it daily), there is still a large proportion, especially among elderly, who struggle with adopting the new technology (Findahl and Davidsson, 2016). We acknowledge this limitation for the general adoption of a BCSS. There is however a strong increase in smartphone ownership worldwide (Pew Research Center, 2016). "Shaping" is where the application should inspire the user to contemplate about her/his current attitudes towards mobility and consider how their personal mobility could be more sustainable. "Changing" is the process in which 


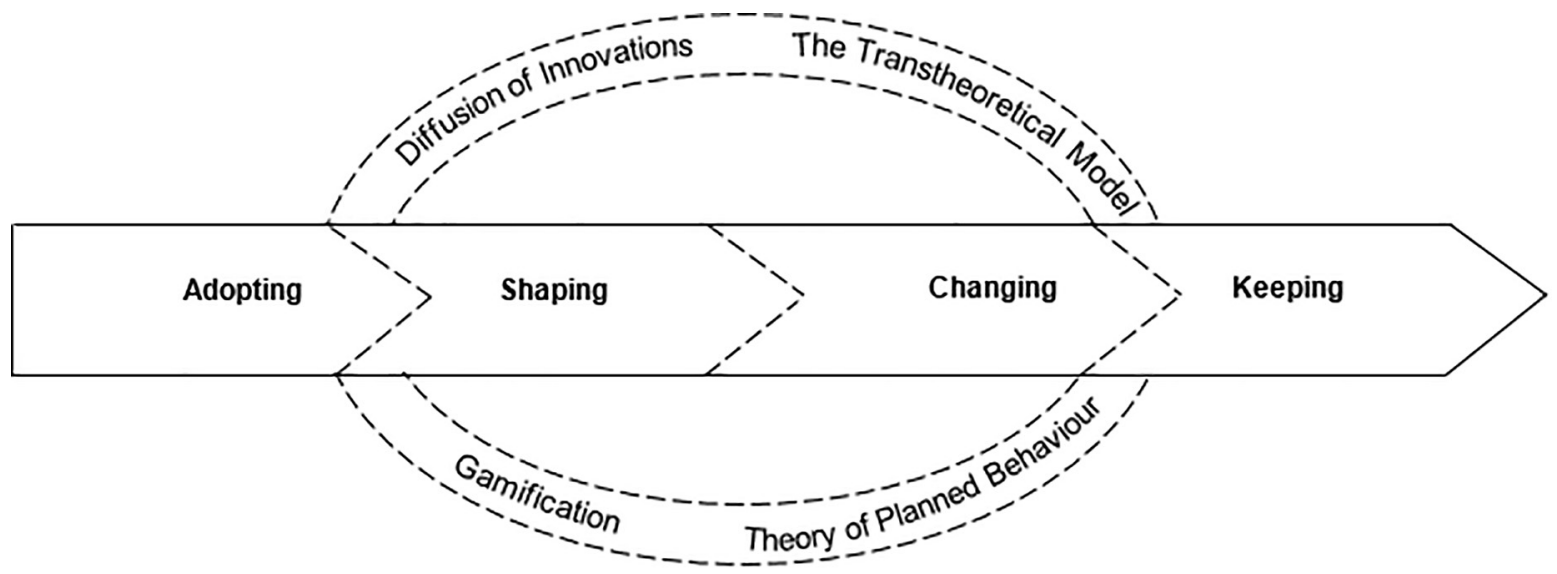

Fig. 1. Theoretical overview of framework application on four integrated stages of behavioural change with the use of a BCSS.

the BCSS ought to guide the user towards accomplishing her/his goals and thus making the necessary changes to succeed. "Keeping" is the final step in which the user might need sustained motivation in order to implement the new behaviour as a habit.

Diffusion of Innovations (Rogers, 1995) is a theory that seeks to explain how innovations are spread within group of societies. According to the theory, innovation could be a behaviour, technology, service, structure, system, an object or idea that is considered by society to be new. Diffusion is the process where innovations is communicated via different channels over time among members of a social system (Rogers, 1995). The theory is particularly valuable in gaining insights in what qualities makes innovations spread, the importance of social networks that spread the word about innovations, as well as the significance of identifying different user segments and their needs.

Theory of Planned Behaviour (TPB) (Ajzen, 1991) is a theory whose purpose is to explain human behaviour. The theory assumes that attitudes towards a certain behaviour, subjective norms and perceived behavioural control together form an individual's intentions and behaviours (ibid.). It has been used in a variety of studies to explain and predict behaviour in fields such as sociology, psychology, environment and health (Anable et al., 2006). TPB is the most common and influential theory used to explore the attitude-behaviour gap (Armitage and Conner, 2001). TPB has also established itself in research on travel behaviours in order to increase the knowledge of how sustainable modal shares can increase through changing behaviours of travellers (Bamberg et al., 2003; Jariyasunant et al., 2012; Semanjski and Gautama, 2016; Semanjski et al., 2016). Semanjski and Gautama (2016) has identified TPB as well-established in research related to Mobility Management, which further motivates for its use as part of a framework to analyse how individuals can be encouraged to more sustainable travel behaviours.

The Transtheoretical Model (TTM) (Prochaska and DiClemente, 1982) is a theory that seeks to explain the process of behaviour change. It considers behaviour change to be a dynamic process rather than an isolated event and consists of several steps. TTM has been used primarily to explain health-related behaviour changes, but in recent years also to understand travellers modal choice (Forward, 2014). Bamberg (2007) for example, used TTM to try to describe the decision-making process for motorists who switched to public transport. The result showed that the expected consequences of the changed travel pattern were perceived as more positive further along the behaviour change process.

Gamification is the use of game elements/game mechanisms in activities that are traditionally unrelated to gaming to enhance the user experience of a particular activity (Deterding et al., 2011). In recent years, the concept has been applied in a number of areas for the purpose of influencing behaviours and increasing the motivational power of the user, but without much consensus on how the concept should be formulated and what the actual benefits are (Seaborn and Fels, 2015). This is also true in the transport sector, where there are a number of examples of scientific studies where attempts have been made to change travel habits using gamification (Castellanos, 2016). The concept is interesting for this study since it brings new perspectives on motivational trigger points which indeed could be combined with data collected via smartphone applications.

\section{Method}

\subsection{Literature review}

A literature search was being conducted on electronic sources in multiple data bases. The review followed PRISMA guidelines (Moher et al., 2009) for literature reviews by including the four phases of the PRISMA flow diagram: Identification, screening, eligibility and included papers evaluation. To obtain multiple perspectives, the search included other fields apart from transport where behaviour change techniques were combined with ICT. Since smartphones today are the most widely used digital tool for travellers to access travel information, (Poslad et al., 2015; Klecha and Gianni, 2018) it made sense to construct keywords that would allow research about application-based ICT for smartphones. The keywords consisted of constructs with different combinations of the terms "travel/transportation/mobility behaviour", "behaviour change", "smartphone/application", "mobile device" and "persuasive technology". The timeframe was set for 2008-2017.

The search were performed in February 2017 and then repeated in September to ensure we covered recent research findings before making final conclusions (see the flow diagram in Fig. 2 for details). The majority were scientific articles and a small number consisted of conference material and dissertations. Three criteria determined whether the literature could be considered relevant to the study or not. To be included in the study, it was required that the material fulfilled the following: (a) it must be peer-reviewed, (b) focused on some form of behaviour change and (c) investigated the use of apps, smartphones or other types of ICT relevant to the study. After fulfilling the search a snowball review was conducted, where references from the articles in the literature search were screened for additional eligible papers. After reconciliation with the above criteria, a total of 32 articles were included in the review to be analysed.

\subsection{Data extraction process using content analysis}

The articles were independently examined for information that provided knowledge of behaviour change with the help of ICT-appliances. This was made through a content analysis, which means analysing data without preconceived categories to allow new insights to emerge (Hsieh and Shannon, 2005). The content was carefully analysed 


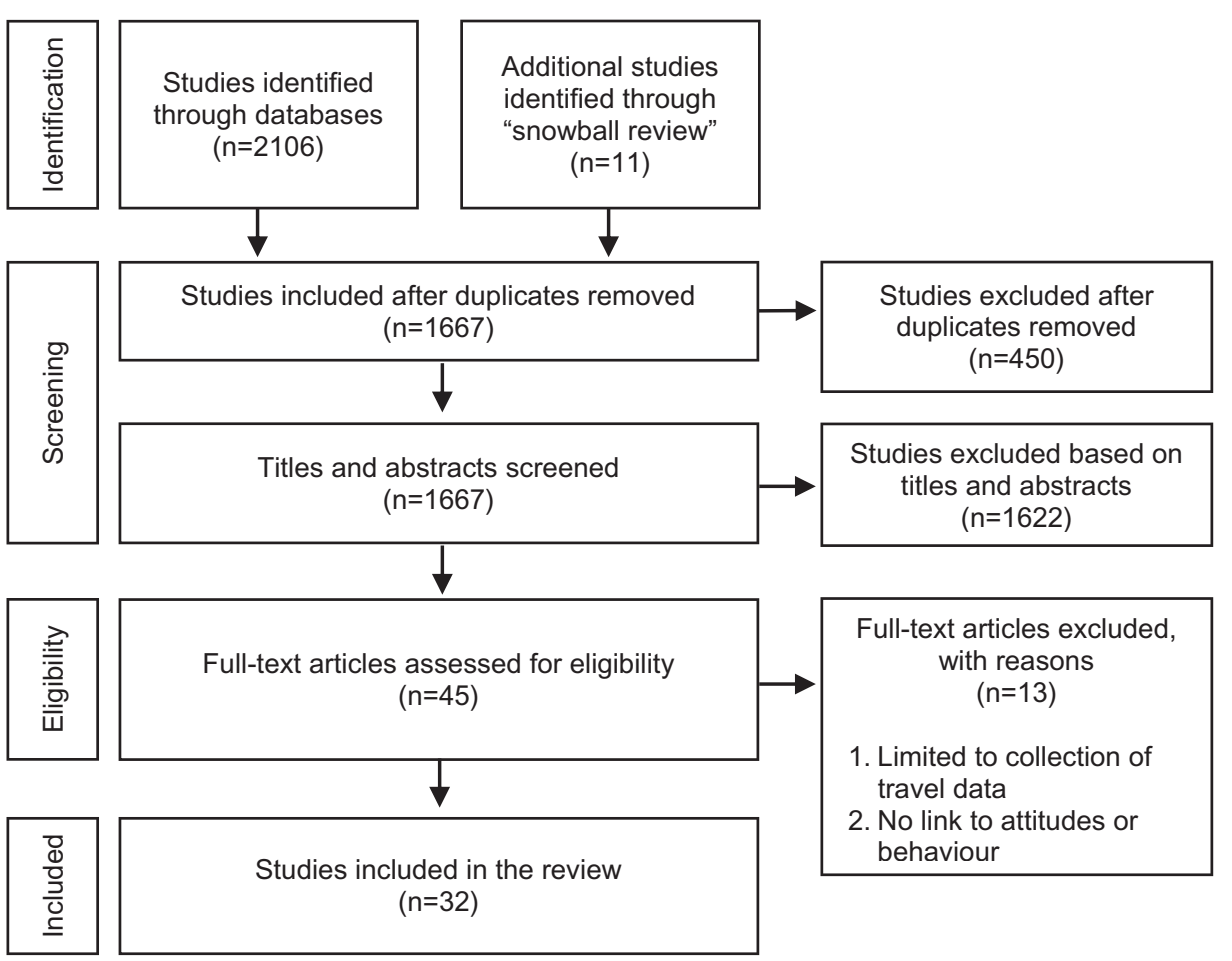

Fig. 2. Study inclusion flow diagram.

to identify key concepts and findings that later could be sorted into categories, also described as inductive category development (Potter and Levine-Donnerstein, 1999). When performing the inductive category development, three researchers took part in a workshop to discuss possible categories and which to go further with. The content analysis was, however, performed by one independent researcher and herein lies potential bias. The categories were tested against the theoretical framework to evaluate if the findings from earlier research correspond with relevant theories or not. From this outcome a conceptual model was constructed, based on empirical evidence and the theoretical framework.

\section{Literature review}

Research on ICT and behavioural change has been conducted in several fields, of which four were investigated in this study. The majority $(27 / 32)$ of the articles concerns transport and mobility or health and fitness while three items are energy-related and two address environmental and climate issues (see Table 1). This means that the following analysis will be strongly characterized by the two first mentioned fields, which however, is of less concern since it is the synthesis of the result that is interesting and not necessarily what the parts say separately. Less than half of the reviewed articles used any kind of theory or concept which suggests a gap between theory and empiricism, where empirical research lacks reference to theory and where theory is not sufficiently rooted in empirical research, which is also recognised in earlier research (Klein et al., 2014; Sunio and Schmöcker, 2017). The theories mentioned, however, are the Theory of Planned Behaviour (Martiskainen and Coburn, 2011; Jariyasunant et al., 2015; Semanjski and Gautama, 2016; Semanjski et al., 2016; Pronello et al., 2017), Random Utility Theory (Brazil and Caulfield, 2013), Rational Choice Theory (Martiskainen and Coburn, 2011), Information-Motivation-Behavioural Skills model (Aliabadi et al., 2016), Gamification (Wells et al., 2014; Poslad et al., 2015; Castellanos, 2016; Coombes and Jones, 2016) and Nudging as well as Behavioural Economics theory (Gilliland et al., 2015).

\section{Analysis}

\subsection{Findings related to the theoretical framework}

From the literature review, 26 findings were identified which concerns different aspects of BCSSs (see Table 2). Upon review of these, four distinctive categories were identified, namely (1) customization to the user, (2) information and feedback, (3) commitment and (4) appealing design. The findings were sorted into these four categories and then analysed based on the theoretical framework of the study.

\subsubsection{Customization to the user}

A recurring observation from the articles is the importance of adapting ICT and behavioural change to the user and its needs, rather than a standard format of one size fits all (ex. Anagnostopoulou et al., 2016; Poslad et al., 2015; Tang et al., 2015; Coşkun and Erbuğ, 2014; Gilliland et al., 2015; Kraft and Yardley, 2009; Dennison et al., 2013; Anda and Temmen, 2014). Several studies also pointed to the need to contextualize the content and thus make it more relevant to the user (Hargreavesn et al., 2010; Coşkun and Erbuğ, 2014; Poslad et al., 2015; Aliabadi et al., 2016; Anagnostopoulou et al., 2016). TPB assumes that individuals' behaviour is influenced by habits but governed by logical reasoning. According to the theory, better information should therefore benefit the individual and strengthen confidence in the innovation at question.

According to Diffusion of Innovations, it is the product that needs to be adjusted to the individual instead of the opposite. Rogers (1995) identified five key criteria that determine between 49 and 87 percent the acceptance of an innovation, namely: its relative advantage over similar products, how well it complies with prevailing norms and values, ease of use and simplicity, if a trial period is offered and if the results can be observed by the user. Rogers (1995) further stated that one needs to understand the needs of the user and adjust innovations to match the requirements of the segment (innovators, early adopters, early majority, late majority, laggards).

Both the reviewed articles and the above-mentioned theories support the findings that focus on adjusting content to the user and can 
Table 1

Compilation of empirical material, by theme, source and purpose.

\begin{tabular}{|c|c|c|}
\hline Theme & Source & Purpose \\
\hline \multirow[t]{3}{*}{ Energy } & Anda \& Temmen (2014) & $\begin{array}{l}\text { Provide examples of how smart energy meters along with community engagement can reduce energy consumption } \\
\text { in households }\end{array}$ \\
\hline & Hargreavesn et al. (2010) & $\begin{array}{l}\text { Qualitative field study on how individuals interact with smart energy meters and how it can affect the behaviour of } \\
\text { consuming less energy }\end{array}$ \\
\hline & Martiskainen \& Coburn (2011) & Identifying which factors contribute most to energy-efficient household use using smart energy meters \\
\hline \multirow[t]{12}{*}{ Health and fitness } & Aliabadi et al. (2016) & Identify desirable features for an application that prevents HIV in men. Focus groups with 33 participants \\
\hline & Baranowski \& Frankel (2012) & $\begin{array}{l}\text { Describe different forms of ICT for behavioural change and its strengths and weaknesses to affect children to more } \\
\text { healthy behaviour }\end{array}$ \\
\hline & Chaplais et al. (2015) & Systematic literature review on the effects of smartphone usage as a tool for treating obesity among children \\
\hline & Chen et al. (2015) & $\begin{array}{l}\text { Evaluate the quality of the most popular health applications and quantify the techniques used to encourage } \\
\text { behaviour change }\end{array}$ \\
\hline & Coombes and Jones (2016) & $\begin{array}{l}\text { Aims to get children more active by encouraging them to walk and cycle in their neighbourhood using tracking } \\
\text { technology with a reward scheme. Evaluates the impact of the "Beat the Street-scheme" on active travel to school in } \\
\text { Norwich, UK }\end{array}$ \\
\hline & Dennison et al. (2013) & $\begin{array}{l}\text { Explore young adults }(n=19) \text { perspective on health and behavioural applications to find out what motivates them } \\
\text { to use such applications. Focus groups and qualitative interviews }\end{array}$ \\
\hline & DiFilippo et al. (2015) & $\begin{array}{l}\text { Systematic literature review to study the nutritional applications' ability to improve adult knowledge and behaviour } \\
\text { about diet and nutrition }\end{array}$ \\
\hline & Fanning et al. (2012) & $\begin{array}{l}\text { Perform a meta-analysis of research that examined ICT to encourage physical activity, evaluate its effectiveness and } \\
\text { provide suggestions on how future implementation should be designed }\end{array}$ \\
\hline & Gilliland et al. (2015) & Investigate the effects of "SmartAPPetite", an application designed to encourage healthy and locally produced food \\
\hline & Kraft \& Yardley (2009) & Compile knowledge and suggest future studies on ICT as a tool for changing health-related behaviour \\
\hline & McKay et al. (2016) & $\begin{array}{l}\text { Systematic literature review on research that examines the impact of health applications on behaviour to identify } \\
\text { best practice }\end{array}$ \\
\hline & Tang et al. (2015) & $\begin{array}{l}\text { Investigate young people's experiences and values of using internet and application-based health information as } \\
\text { well as what they value in the context }\end{array}$ \\
\hline \multirow[t]{2}{*}{ Climate and environment } & Coşkun \& Erbuğ (2014) & $\begin{array}{l}\text { Investigate which app features are important to successfully encourage and long-term sustainable choices based on } \\
17 \text { users' recommendations of four different applications }\end{array}$ \\
\hline & Sullivan et al. (2016) & $\begin{array}{l}\text { Quality assessment of existing travel and dietary apps capable of calculating CO2 emissions and health effects to } \\
\text { influence behaviour change }\end{array}$ \\
\hline \multirow[t]{15}{*}{ Transport and mobility } & Anagnostopoulou et al. (2016) & $\begin{array}{l}\text { A review of existing approaches and prototype systems which describes and classifies the persuasive strategies used } \\
\text { for changing behaviour in the domain of transport. Also examines the results and recommendations derived from } \\
\text { pilot studies }\end{array}$ \\
\hline & Berger \& Platzer (2015) & $\begin{array}{l}\text { Evaluate "SmartMo" as a tool for collecting travel behaviour data and gain insights on their attitudes towards the } \\
\text { application. } 97 \text { participants in the study }\end{array}$ \\
\hline & Bothos et al. (2014) & $\begin{array}{l}\text { Focus on persuasive strategies supported by a choice architecture approach and incorporated in a smartphone } \\
\text { application, aiming at providing urban travellers with a solution that will influence them to consider sustainable } \\
\text { options }\end{array}$ \\
\hline & Brazil \& Caulfield (2013) & Investigate the impact of travel and $\mathrm{CO} 2$ calculators on users' travel behaviour \\
\hline & Bresciani et al. (2016) & $\begin{array}{l}\text { Presented the projects "Opti-LOG" and "Sharing Cities", which are joint-venture collaborative projects to initiate } \\
\text { more sustainable mobility and energy-saving society through behavioural change. The project includes public and } \\
\text { private actors as well as community citizens }\end{array}$ \\
\hline & Castellanos (2016) & $\begin{array}{l}\text { Study the effects of financial incentives via mobile phones to encourage more sustainable travel. } 20 \text { participants in } \\
\text { the study for two weeks }\end{array}$ \\
\hline & Jariyasunant et al. (2015) & $\begin{array}{l}\text { Describe the development, application and analysis of a computational travel feedback system called Quantified } \\
\text { Traveller (QT). }\end{array}$ \\
\hline & Klecha and Gianni (2018) & $\begin{array}{l}\text { A review of } 14 \text { different applications with focus on utilised technology, behaviour change strategies and citizen } \\
\text { participation in the development process. }\end{array}$ \\
\hline & Parvaneh et al. (2014) & $\begin{array}{l}\text { Study the effects of personal travel information, taking into consideration personal preferences. Comparative } \\
\text { descriptive and normative travel information }\end{array}$ \\
\hline & Poslad et al. (2015) & $\begin{array}{l}\text { Study the impact on the behaviour of various travel incentives through the use of Tripzoom in the European cities of } \\
\text { Enschede, Gothenburg and Leeds for six months }\end{array}$ \\
\hline & Pronello et al. (2017) & $\begin{array}{l}\text { Assessing the effects on travel behaviour of a multimodal real-time information navigator for smartphone, } \\
\text { developed within the project Optimod'Lyon }\end{array}$ \\
\hline & Semanjski et al. (2016) & $\begin{array}{l}\text { Examine the potential of smartphones as tools to deliver incentives to achieve a more sustainable travel behaviours, } \\
\text { as well as identify different attitude profiles. } 3400 \text { participants over six months }\end{array}$ \\
\hline & Semanjski \& Gautama (2016) & $\begin{array}{l}\text { To bridge psychology, marketing and ICT in transport research and evaluate the automatic segmentation of the } \\
\text { eight attitude profiles within SEGMENT }\end{array}$ \\
\hline & Sunio and Schmöcker (2017) & $\begin{array}{l}\text { Review of existing behaviour change support systems (BCSS) designed to promote sustainable travel behaviour. } \\
\text { Extracts the persuasive features and evaluate their persuasive potential by using the persuasive systems design } \\
\text { (PSD) model that has been used to evaluate BCSSs in the health domain. }\end{array}$ \\
\hline & Wells et al. (2014) & To develop a platform that, using gamification, encourage users to reflect on their travel behaviours \\
\hline
\end{tabular}

thus be seen as an important component in the development of a BCSS. Individual alignment is in line with TTM, which divides the five-stage transition process (pre-contemplation, contemplation, preparation, action, maintenance) to determine at which stage of the process individuals are. The eight attitude profiles (Semanjski et al., 2016) uses similar approach as they segment the users according to their attitude towards sustainable travel modes. In this manner, information, feedback and incentives can be adjusted depending on whether the user is in an early or late stage of the behaviour change process.
According to TPB, it is possible to influence the intentions of individuals by influencing and drastically changing the prerequisites for one or more of the three components: the individual's attitude and values towards the behaviour, the social norm in relation to the behaviour and experienced control of performing the action (Bamberg et al., 2003). By contextualizing and customizing content in, for example, an application for smartphones, the perceived control should increase as the individual will be equipped with more relevant information. 
Table 2

Categorization of findings from the literature review.

\begin{tabular}{ll}
\hline Category & Findings \\
\hline $\begin{array}{l}\text { Customization to the } \\
\text { user }\end{array}$ & 1. Applications should customize information, goals and challenges \\
2. Use of attitude profiles increases knowledge about which segments are \\
more willing to change travel behaviour \\
3. Contextualization is important to the user \\
4. The focus should be on the whole household rather than just the \\
individual \\
5. Perceived control is an important factor in the choice of performing a \\
certain behaviour \\
6. Participatory design methods, in which end-users actively participate in \\
the stages of design and development of BCSS, is unusual but could \\
increase acceptance and usefulness of the application \\
7. It is unclear whether normative information is better than descriptive in \\
trying to influence behaviour change \\
8. Reflective learning could be an alternative approach to persuasion \\
9. Credible information and data is important to the user
\end{tabular}

10. Measurement and overview of behaviour is important to the user

11. Mobility is very habitual and information can play a role in shifting modes only if it becomes meaningful enough to give users significant reasons to break their routine, changing the cognitive foundation of intentions and behaviour

12. Feedback is important for the user to change behaviour

13. Applications should provide relevant knowledge of environmental and climate-smart behaviour according to users

14. Incentives in the form of reward can work both positively and negatively when trying to influence behaviours

15. Carbon dioxide calculators have little effect on travellers if they for example value short travel times higher than low $\mathrm{CO} 2$ emissions, but can be useful for comparing modes and increase awareness of unsustainable behaviour

16. Incentives that are not linked to any product do not seem to inspire behavioural change to a greater extent in some segments

17. Daily reminders do not necessarily have a positive effect on the quality of data collection

Commitmen

18. Higher motivation and involvement leads to a greater extent to positive results

19. Gamification can extend the commitment of the user

20. Gamification does not necessarily increase sustainable travel in itself but on the other hand increases engagement at least in a short perspective 21. Long-term commitment is a key issue for ICT to change and maintain the behaviour of the user

22. Applications need to be fun to engage some users 23. Gamification that challenges and triggers contest behaviours could be used for motivational purpose

Appealing design

Source

(Kraft and Yardley, 2009; Dennison et al., 2013; Anda and Temmen, 2014; Coşkun and Erbuğ, 2014; Gilliland et al., 2015; Poslad et al., 2015; Tang et al., 2015; Anagnostopoulou et al., 2016)

(Anagnostopoulou et al., 2016; Semanjski and Gautama, 2016; Semanjski et al., 2016)

(Hargreavesn et al., 2010; Coşkun and Erbuğ, 2014; Poslad et al., 2015;

Aliabadi et al., 2016; Anagnostopoulou et al., 2016)

(Hargreavesn et al., 2010; Anda and Temmen, 2014)

(Coșkun and Erbuğ, 2014)

(Klecha and Gianni, 2018)

(Parvaneh et al., 2014)

(Bothos et al., 2014; Klecha and Gianni, 2018)

(Hargreavesn et al., 2010; Dennison et al., 2013; Anda and Temmen, 2014; Coşkun and Erbuğ, 2014; Gilliland et al., 2015; Tang et al., 2015; Aliabadi et al., 2016; Anagnostopoulou et al., 2016)

(Martiskainen and Coburn, 2011; Dennison et al., 2013; Gilliland et al., 2015; Tang et al., 2015)

(Bothos et al., 2014; Coombes and Jones, 2016; Pronello et al., 2017)

(Kraft and Yardley, 2009; Hargreavesn et al., 2010; Dennison et al., 2013; Anda and Temmen, 2014; Bothos et al., 2014; Gilliland et al., 2015; Poslad et al., 2015; Tang et al., 2015)

(Dennison et al., 2013; Coşkun and Erbuğ, 2014; Gilliland et al., 2015)

(Coşkun and Erbuğ, 2014)

(Brazil and Caulfield, 2013; Bothos et al., 2014)

(Poslad et al., 2015)

(Berger and Platzer, 2015)

(Kraft and Yardley, 2009; Hargreavesn et al., 2010; Martiskainen and Coburn, 2011; Gilliland et al., 2015; Jariyasunant et al., 2015; Castellanos, 2016; Coombes and Jones, 2016)

(Kraft and Yardley, 2009; Baranowski and Frankel, 2012; Berger and Platzer, 2015; Chaplais et al., 2015; DiFilippo et al., 2015; Poslad et al., 2015; Castellanos, 2016)

(Wells et al., 2014; Coombes and Jones, 2016)

(Kraft and Yardley, 2009; Martiskainen and Coburn, 2011; Baranowski and Frankel, 2012; Chaplais et al., 2015; DiFilippo et al., 2015; Gilliland et al., 2015; Castellanos, 2016; Coombes and Jones, 2016; Pronello et al., 2017) (Dennison et al., 2013; Aliabadi et al., 2016)

(Coşkun and Erbuğ, 2014; Wells et al., 2014; Chen et al., 2015)

(Hargreavesn et al., 2010; Martiskainen and Coburn, 2011; Dennison et al., 2013; Coşkun and Erbuğ, 2014; Berger and Platzer, 2015; Poslad et al., 2015; Tang et al., 2015; Aliabadi et al., 2016; Klecha and Gianni, 2018) (Dennison et al., 2013; Berger and Platzer, 2015; Aliabadi et al., 2016; Castellanos, 2016)

(Fanning et al., 2012; Wells et al., 2014; Gilliland et al., 2015; Poslad et al., 2015; Semanjski et al., 2016; Sullivan et al., 2016)

\subsubsection{Information and feedback}

Information and feedback emerged as an important category for encouraging individuals to perform the desired behaviour (Kraft and Yardley, 2009; Hargreavesn et al., 2010; Dennison et al., 2013; Anda and Temmen, 2014; Coșkun and Erbuğ, 2014; Gilliland et al., 2015; Poslad et al., 2015; Tang et al., 2015; Aliabadi et al., 2016). Most importantly, credible information and data were considered important as well as the ability to measure their performance and get feedback on one's behaviour in relation to individualized goals. Incentives/rewards may be necessary for individuals to switch to more sustainable means of travel (Poslad et al., 2015), but can also be counterproductive if they are perceived as unnecessary or irrelevant (Coşkun and Erbuğ, 2014).

According to TTM, individuals who undergo the behavioural change stages continuously assess the balance between the pros and cons of the changed behaviour (decisional balance) (Prochaska and DiClemente, 1982). Information and feedback can therefore be used to clarify the benefits of the change and counter-argue the disadvantages. This balance is different through the change process, for example, the cons of 
the new behaviour have more weight for individuals during pre-contemplation. However, in the next stage of contemplation, individuals are more likely to understand the benefits of the changed behaviour but still overestimate the effort/costs of the change and are thus still ambivalent in their behaviour and not yet quite ready for the change (Bamberg, 2007). Thus, in the first stages, focus should be on raising the positive aspects of sustainable travel and providing credible information that reinforces these arguments in combination with short-term rewards (Forward, 2014). In the third stage, preparation, the benefits have become quite obvious to the individual, though one could still experience the change difficult, which means that they may need guidance to move on to the next stage. In the action stage, the experience of the new behaviour has probably shown that it was easier than expected and the benefits were reminiscent. At this stage, however, the new behaviour has not yet become a habit, which is why it is important that the experience feels good and rewarding to avoid the risk of the individual returning to old behaviour patterns.

According to TPB, behaviours can be predicted by individuals' attitude towards the action and their perceived control, that is, their experience of how capable they are to perform the action (Ajzen, 1991). With this in mind, information and feedback within BCSSs should be designed to positively affect the attitude towards sustainable travel and also aim to strengthen individuals' belief that they are capable of actually replacing the car in favour of walking, cycling or public transport. For example, information about the consequences of an action can influence attitudes in a targeted direction (Abraham and Michie, 2008). In spite of this knowledge, the question remains on how normative information should be. A number of studies express the importance of normalizing sustainable travel so that individuals and society sees the unsustainable alternative as different - not the contrary (Oinas-kukkonen, 2010; Hiselius and Rosqvist, 2016). Also, the Theory of Planned Behaviour sets the social norm as a factor individuals take into account in their choice of behaviour, indicating that it would be a good idea to influence these via normative information (Bamberg et al., 2003). At the same time, the risk that individuals may ignore information could be greater at normative than descriptive information, as it could be perceived as less objective and more deceptive (Parvaneh et al., 2014). An alternative approach to normative and persuasive information could be that of reflective learning, which advocates systems to "foster openended reflection, meaning for users to reflect on what it actually means to be sustainable in a way that makes sense in the context of their own lives" (Klecha and Gianni, 2018). The question of which information that would be appropriate and adapted by the user may depend on which user segment the individual belongs to, which again stresses the importance of appropriate segmentation techniques.

\subsubsection{Commitment}

Engaging the user appears as a key issue when it comes to changing behaviours using ICT (Kraft and Yardley, 2009; Martiskainen and Coburn, 2011; Baranowski and Frankel, 2012; Chaplais et al., 2015; DiFilippo et al., 2015; Gilliland et al., 2015; Castellanos, 2016; Coombes and Jones, 2016; Klecha and Gianni, 2018). After all, it seems to be of less significance if an application is sophisticated as long as users neglect it because it is uninteresting. A number of studies highlighted the problem of declining application interest rates over time, as long term involvement on the other hand more often leads to positive results (Kraft and Yardley, 2009; Hargreavesn et al., 2010; Martiskainen and Coburn, 2011; Gilliland et al., 2015; Jariyasunant et al., 2015; Castellanos, 2016; Pronello et al., 2017). For example, Pronello et al. (2017) found that mobility is a highly habitual activity which is not easily interrupted, except for short periods. This analysis is in line with TTM, which means that behavioural change is a process that takes time and thus requires long-term commitment (Prochaska and DiClemente, 1982). According to TTM, the change process is not linear, but is often characterized by several relapses to old behaviour patterns (Bamberg, 2007). Diffusion of innovations also points out the renewal of products as a central principle for successful dissemination and long-term survival of innovations (Rogers, 1995; Robinson, 2009). Continuous improvements are here pointed out as important for maintaining consumer interest and commitment over time (Robinson, 2009) and should ideally be carried out during stages of design and development with input from actual users (Klecha and Gianni, 2018).

Several studies are optimistic about Gamification and its potential to extend the commitment of the user (Kraft and Yardley, 2009; Baranowski and Frankel, 2012; Berger and Platzer, 2015; Chaplais et al., 2015; DiFilippo et al., 2015; Poslad et al., 2015; Castellanos, 2016). That gamification would have a positive impact on participants' involvement is also supported by Seaborn \& Fels (2015). The gaming industry has succeeded in motivating its target groups with mechanisms that provide constant feedback and motivate individuals to reach a distant goal. It is those processes that gamification could use to build a digital platform around something real. What is needed is data, and since large quantities can be gathered via, for example, travel applications, the possibility to gamify the experience should be virtuous. At this point however, research have not been able to determine which specific game elements work best to prolong commitment (Berger and Platzer, 2015; Poslad et al., 2015; Castellanos, 2016). It probably also depends on context and what kind of attitude profile is the target group for behavioural change (Seaborn and Fels, 2015).

\subsubsection{Appealing design}

Throughout the articles, the importance of an appealing and simple design of BCSSs was emphasized to keep the interests of users (Hargreavesn et al., 2010; Martiskainen and Coburn, 2011; Dennison et al., 2013; Bothos et al., 2014; Coşkun and Erbuğ, 2014; Berger and Platzer, 2015; Poslad et al., 2015; Tang et al., 2015; Aliabadi et al., 2016). Designing to create user-friendliness is thus important for users to quickly understand and be able to use the application. Some studies found that individuals also appreciate the ability to personalize the design, thus improving the adaptation to the user.

Gamification can, as mentioned earlier, be used to increase user involvement. This can also be reflected in the design of the application. According to Seaborn \& Fels (2015), game elements should have a usercentred approach, where external rewards, points, pins and/or marks should be based on the users' motivational trigger points.

Simplicity and ease of use are one of the five key criteria that affect the acceptance of an innovation, according to Diffusion of Innovations theory (Robinson, 2009). New ideas and innovations that are easy to understand are accepted earlier than those that require the user to develop new skills.

But while focusing on simplicity, a number of studies have also shown the importance of respecting the integrity of the user (Dennison et al., 2013; Berger and Platzer, 2015; Aliabadi et al., 2016; Castellanos, 2016). The processing of collected data must respect user integrity and ensure that sensitive information remains accessible only for intended actors. Clarifying this in the design should be central to ensure that individuals are comfortable using the application.

\subsection{Developing a conceptual model for behaviour change support systems}

After analysing the four categories via the theoretical framework, they all appear as adequate for creating a conceptual model that helps us to better understand what considerations are important when constructing a BCSS (Fig. 3). First of all, customization to the user appear to be crucial in order to contextualise information, feedback, goal setting, stimuli, motivational mechanisms and other content within the BCSS. For that reason, "Customization to the user" is the starting point of our conceptual model and also an influencer of "Information and feedback" and "Commitment", since both of these parts should be grounded in the users' needs as well. Our approach is that these three parts in combination will contribute to an "Appealing design", which in itself also needs to be simple and user friendly. The arrow design is a reminder 


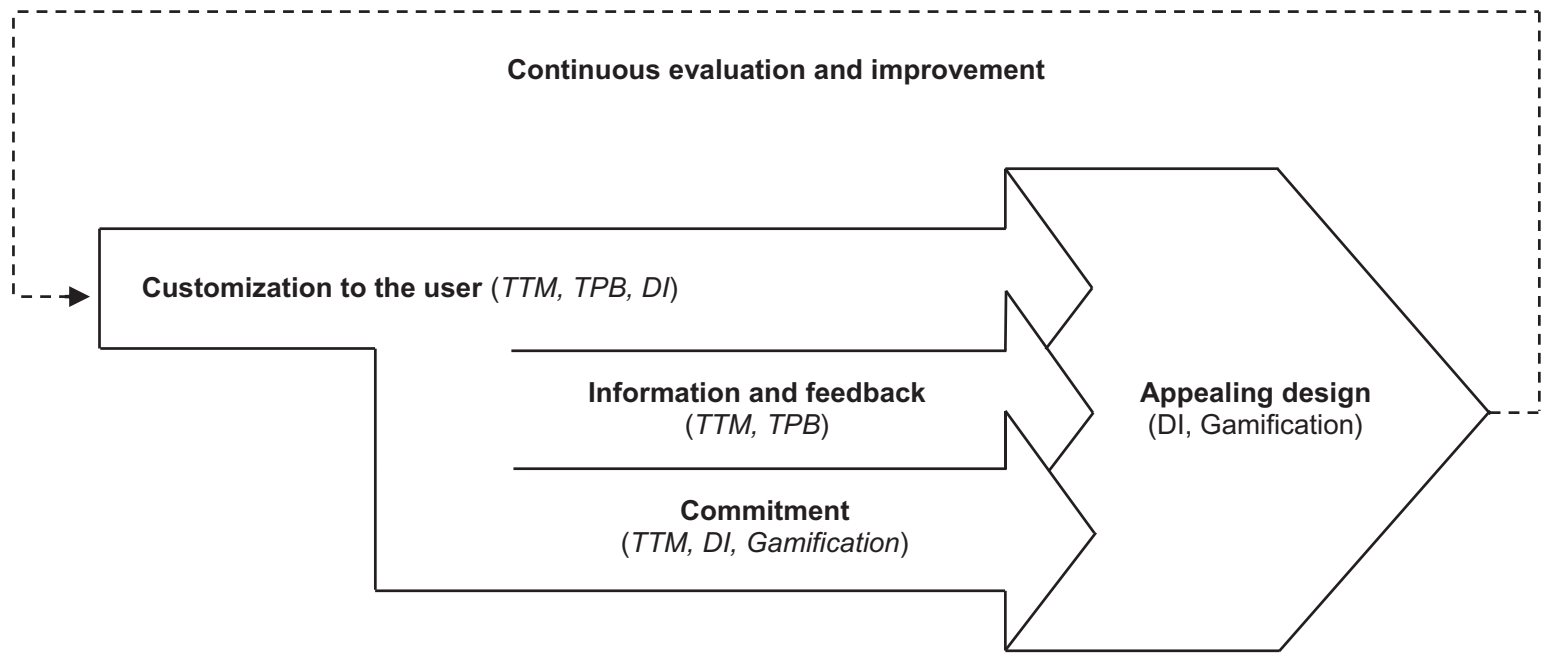

Fig. 3. A conceptual model for combining behavioural change techniques with ICT to create a BCSS

that the development of BCSSs is a process rather than a "quick fix", which benefits from continuous evaluation and improvement, preferably with input from the users themselves (Klecha and Gianni, 2018).

The suggested model can be used to guide the implementation process of behaviour change techniques into smartphone applications to create a BCSS. It has a user-centred focus and advocates that information, goals and feedback is adjusted to individuals through segmentation techniques. In this way, chances are greater that the user is provided with contextual and relevant content that is useful to individuals (Anagnostopoulou et al., 2016). The model emphasizes the importance of engaging the user to maintain motivation through the behavioural change process. Motivating the user is important because the performance has proven to be better the higher the interaction with the application is (Kraft and Yardley, 2009; Martiskainen and Coburn, 2011; Gilliland et al., 2015; Castellanos, 2016). A simple and userfriendly interface should characterize the design itself.

The model uses established theories (TTM, TPB, DI) and Gamification as support functions in the different parts of the model. The categories are visualized together with the theories/concept that have been used in verifying and developing the findings from the literature review. The purpose of including these is to clarify what perspectives that has characterized the different parts of the conceptual model. Generally, the behaviour change theories TTM and TPB are most influential in the first parts of the model. The reverse applies to Gamification, which is more relevant when it comes to creating processes that involve the user, as well as in designing and visualize content. Diffusion of Innovations emphasizes the importance of starting from the consumer, constantly renewing innovation to create long-term commitment, as well as designing products that are simple and userfriendly (Rogers, 1995). This theory is thus well suited to keep in mind through the entire development process.

\section{Discussion}

The purpose of this study was to investigate how behaviour change techniques can be combined with ICT in the creation of a BCSS that encourage sustainable travel behaviour, as well as developing a conceptual model that highlights important aspects to take into account in such an implementation process. The results contributed in its entirety to answering the questions that guided the research process.

Previous research points to ICT in general, and smartphone-applications in particular, as a promising tool for influencing behaviour change. The results indicate, however, that it requires a user-centred focus, providing individuals with information, feedback and goals relevant for their specific needs to be of value in the process of changing behaviour. This is in line with the persuasive systems design (PSD) model (Oinas-kukkonen and Harjumaa, 2009), which represents an extensive conceptualization for technology-based persuasion (for further application of the model, see Sunio and Schmöcker, 2017). To allow for relevant and contextualised contents, segmentation of target population would indeed be essential, which also goes in line with earlier research on conventional Mobility Management campaigns (Meloni et al., 2017).

Some studies indicated that the change was more successful the more individuals used and interacted with the intended BCSS (Kraft and Yardley, 2009; Hargreavesn et al., 2010; Martiskainen and Coburn, 2011; Gilliland et al., 2015; Castellanos, 2016; Coombes and Jones, 2016). Commitment over time thus emerged as one of the most important factors for successfully influence behaviour change. However, previous research also stressed the need for more empirical research on how long-term commitment is achieved. Gamification seems promising and several studies recommend further research in this area (Berger and Platzer, 2015; Poslad et al., 2015; Castellanos, 2016). The theoretical framework contributed to verifying and developing the results obtained in the literature review. TTM supports an individualized approach and segmentation. The theory can also explain to some extent how information and feedback should be designed based on the users' motivational balance that characterizes the transition between the behaviour change stages (see 5.1.2). It also supports the observation that long-term commitment is important for individuals to complete the change process and to reduce the risk of relapse into old habits. According to Theory of Planned Behaviour, attitudes towards behaviour, social norms and perceived control are the main influencers of individuals' behaviours. Customized information and feedback that reinforces the user's perceived control, as well as content that normalizes sustainable mobility choices should therefore be advocated by the theory. However, TPB is unable to explain more closely how normative information and feedback should be. Diffusion of innovations supports segmentation, customization to the user, continuous improvement to create commitment as well as simplicity and user-friendliness. It also advocates proliferation through social channels, which is supported by some of the reviewed articles and supported by (Ploderer et al., 2014) although no conclusive studies are not yet available to shed light of the efficacy of social channels in BCSS (Sunio and Schmöcker, 2017). Gamification emphasizes the importance of creating processes that induce motivation and commitment, based on the users' motivational trigger points. The challenge with that approach is to know what the individual motivational driving force is. An alternative is to use different attitude segments instead and design the application so that users can customize 
certain parts as they like. The concept seems promising based on previous empirical studies but is also at an early stage, where more research is necessary to understand which processes work best.

\section{Conclusions and further research}

Based on previous research and theory, a conceptual model that highlights key aspects to consider when creating a behaviour change support system (BCSS) were developed. Customization to the user, contextualised information and feedback, commitment and appealing design emerged as essential aspects when developing persuasive smartphone applications. We strongly suggest segmentation of intended target population to enable better customization to the user. This would provide enhanced conditions for user-centred information campaigns, tailor-made objectives and more contextualised content. In previous research on ICT to influence behaviour change, there are several examples of how parts of our conceptual model have been used fragmentarily, usually with mixed results. To the best of our knowledge, there is yet no study on BCSS that takes a holistic approach grounded in theory. It would therefore be potential to work on the model empirically to investigate its appropriateness to influence behaviour change, as theory-based research has showed to be more effective than purely working with behaviour techniques (Webb et al., 2010).

An observation that permeates the reviewed articles is the need for more research with larger and more extensive data collection to enable generalisations on the efficacy of BCSSs to change behaviours. We advocate more empirical studies to be grounded in behaviour theory. Gamification seems to be promising for sustained user engagement, but require further research to conclude what particular mechanisms that should be implemented. We also stress the need for studies exploring adequate segmentation techniques related to mobility, developing tailored messages and content for different segments and also evaluating the effects of these.

Finally, future research should continue to explore the important possibility of measuring actual travel behaviour change with the use of smartphone technology. A successful tool for collecting travel data by smartphones would be essential, in particular for quantitative research, but also for making informed planning decisions regarding mobility ahead.

\section{Disclosure of interest}

The authors declares that there has been no conflicts of interest concerning this article.

\section{References}

Abraham, C., Michie, S., 2008. A taxonomy of behavior change techniques used in interventions. Health Psychol. 27 (3), 379-387. http://dx.doi.org/10.1037/0278-6133. 27.3.379.

Van Acker, V., Van Cauwenberge, B., Witlox, F., 2013. MaxSUMO: a new expert approach for evaluating mobility managament projects. Promet-Traffic Transport. 25 (3), 285-294. http://dx.doi.org/10.7307/ptt.v25i3.290.

Ajzen, I., 1991. The theory of planned behavior. Organ. Behav. Human Decis. Process. 50 (2), 179-211. http://dx.doi.org/10.1016/0749-5978(91)90020-T.

Aliabadi, N., et al., 2016. Using the information-motivation-behavioral skills model to guide the development of an HIV prevention smartphone application for high-risk MSM. AIDS Educ. Prev. 27 (6), 522-537. http://dx.doi.org/10.1521/aeap.2015.27.6. 522

Anable, J., Lane, B., Kelay, T., 2006. 'An evidence base review of public attitudes to climate change and transport behaviour', London, Department for Transport, (July). Available at: http://www.pdfwww.china-up.com:8080/international/case/case/ 1457.pdf.

Anagnostopoulou, E., et al., 2016. Persuasive Technologies for Sustainable Urban Mobility. Persuasive 2016 Workshop: Where are we bound for? Persuasion in Transport Applications. July.

Anda, M., Temmen, J., 2014. Smart metering for residential energy efficiency: the use of community based social marketing for behavioural change and smart grid introduction. In: Renew. Energy 67. pp. 119-127. http://dx.doi.org/10.1016/j.renene. 2013.11.020.

Armitage, C.J., Conner, M., 2001. Efficacy of the theory of planned behaviour. Br. J. Soc.
Psychol. 40 (February 2017), 471-499. http://dx.doi.org/10.1348/ 014466601164939.

Arnott, B., et al., 2014. Efficacy of behavioural interventions for transport behaviour change: systematic review, meta-analysis and intervention coding. Int. J. Behav. Nutr. Phys. Activity 11 (1), 133. http://dx.doi.org/10.1186/s12966-014-0133-9.

Bamberg, S., 2007. Is a stage model a useful approach to explain car drivers' willingnes to use public transportation? J. Appl. Soc. Psychol. 37 (8), 1757-1783. http://dx.doi. org/10.1111/j.1559-1816.2007.00236.x.

Bamberg, S., Ajzen, I., Schmidt, P., 2003. Choice of travel mode in the theory of planned behavior: the roles of past behavior, habit, and reasoned action. Basic Appl. Soc. Psychol. 25 (3), 175-187. http://dx.doi.org/10.1207/S15324834BASP2503_01.

Banister, D., 2011. Cities, mobility and climate change. J. Transp. Geogr. 19 (6), 1538-1546. http://dx.doi.org/10.1016/j.jtrangeo.2011.03.009.

Baranowski, T., Frankel, L., 2012. Let's get technical! Gaming and technology for weight control and health promotion in children. Childhood Obes. (Print) 8 (1), 34-37. http://dx.doi.org/10.1089/chi.2011.0103.

Berger, M., Platzer, M., 2015. Field evaluation of the smartphone-based travel behaviour data collection app "smartMo". In: Transp. Res. Proc. 11. pp. 263-279. http://dx.doi. org/10.1016/j.trpro.2015.12.023.

Bothos, E., et al, 2014. Watch your emissions: Persuasive strategies and choice architecture for sustainable decisions in urban mobility. PsychNol. J. 12 (3), 107-126.

Brazil, W., Caulfield, B., 2013. Does green make a difference: The potential role of smartphone technology in transport behaviour. Transport. Res. Part C: Emerg. Technol. 37 (December), 93-101. http://dx.doi.org/10.1016/j.trc.2013.09.016.

Bresciani, C., et al., 2016. 'Behavioral change and social innovation through reward: an integrated engagement system for personal mobility, Urban Logistics and Housing Efficiency. Transport. Res. Proc. 14, 353-361. http://dx.doi.org/10.1016/j.trpro. 2016.05.087.

Cairns, S., et al., 2008. Smarter choices: Assessing the potential to achieve traffic reduction using "Soft measures". Transp. Rev. 28 (5), 593-618. http://dx.doi.org/10. $1080 / 01441640801892504$.

Castellanos, S., 2016. 'Delivering modal-shift incentives by using gamification and smartphones: A field study example in Bogota, Colombia. Case Stud. Transp. Policy 4 (4), 269-278. http://dx.doi.org/10.1016/j.cstp.2016.08.008.

Chaplais, E., et al., 2015. Smartphone interventions for weight treatment and behavioral change in pediatric obesity: a systematic review. Telemed. J. E-health 21 (10), 822-830. http://dx.doi.org/10.1089/tmj.2014.0197.

Chen, J., Cade, J.E., Allman-Farinelli, M., 2015. The most popular smartphone apps for weight loss: a quality assessment. JMIR mHealth uHealth 3 (4), e104. http://dx.doi. org/10.2196/mhealth.4334.

Coombes, E., Jones, A., 2016. Gamification of active travel to school: a pilot evaluation of the Beat the Street physical activity intervention. Health Place 39, 62-69. http://dx. doi.org/10.1016/j.healthplace.2016.03.001.

Coșkun, A., Erbuğ, C.., 2014. Designing for behaviour change: smart phone applications as persuaders of pro-environmental behaviours. Metu J. Facul. Architect. 31 (1) 215-233. http://dx.doi.org/10.4305/METU.JFA.2014.1.11.

Dennison, L., et al., 2013. Opportunities and challenges for smartphone applications in supporting health behavior change: qualitative study. J. Med. Internet Res. 15 (4), 1-12. http://dx.doi.org/10.2196/jmir.2583.

Deterding, S., et al., 2011. Gamification: Using Game Design Elements in Non-Gaming Contexts. In: Proceedings of the 2011 annual conference extended abstracts on Human factors in computing systems - CHI EA '11. Vancouver, BC, http://dx.doi.org/ 10.1145/1979742.1979575.

DiFilippo, K.N., et al., 2015. The use of mobile apps to improve nutrition outcomes: a systematic literature review. J. Telemed. Telecare 21 (5), 243-253. http://dx.doi. org/10.1177/1357633X15572203.

Environmental Protection Agency Emissions of greenhouse gases from domestic transport Available at: http://www.naturvardsverket.se/Sa-mar-miljon/Statistik-A-O/ Vaxthusgaser-utslapp-fran-inrikes-transporter/2016 Accessed: 1 February 2017.

Fanning, J., Mullen, S.P., Mcauley, E., 2012. Increasing physical activity with mobile devices: a meta-analysis. J. Med. Internet Res. 14 (6). http://dx.doi.org/10.2196/ jmir.2171.

Findahl, O., Davidsson, P., 2016. Swedes and internet 2016: study of Swedes' internet habits. Found. Internet Infrastruct. Sweden 978-91-85291-14-4.

Forward, S.E., 2014. Exploring people's willingness to bike using a combination of the theory of planned behavioural and the transtheoretical model. Revue Europeene de Psychologie Appliquee 64 (3), 151-159. http://dx.doi.org/10.1016/j.erap.2014.04. 002 .

Gerike, R., et al., 2016. Physical Activity through Sustainable Transport Approaches (PASTA): a study protocol for a multicentre project. BMJ Open 6 (1), e009924. http://dx.doi.org/10.1136/bmjopen-2015-009924.

Gilliland, J., et al., 2015. Using a smartphone application to promote healthy dietary behaviours and local food consumption. BioMed Res. Int. 2015. http://dx.doi.org/10. $1155 / 2015 / 841368$.

Government Offices of Sweden The government proposes historical climate reform for Sweden Available at: http://www.regeringen.se/pressmeddelanden/2017/02/regeringen-foreslar-historisk-klimatreform-for-sverige/2017 Accessed: 14 February 2017.

Hargreavesn, T., Nye, M., Burgess, J., 2010. Making energy visible: a qualitative field study of how householders interact with feedback from smart energy monitors. Energy Policy 38 (10), 6111-6119. http://dx. doi.org/10.1016/j.enpol.2010.05.068.

Hiselius, L.W., Rosqvist, L.S., 2016. Mobility Management campaigns as part of the transition towards changing social norms on sustainable travel behavior. J. Clean. Prod. 123, 34-41. http://dx.doi.org/10.1016/j.jclepro.2015.08.055.

Hsieh, H.-F., Shannon, S.E., 2005. Three approaches to qualitative content analysis. Qual. Health Res. 15 (9), 1277-1288. http://dx.doi.org/10.1177/1049732305276687.

IEA (2016) CO2 Emissions from Fuel Combustion - Highlights. Paris. Available at: 
https://www.iea.org/publications/freepublications/publication/ CO2EmissionsfromFuelCombustion Highlights 2016.pdf.

Fogg, J., Eckles, D., 2007. Mobile Persuasion: 20 Perspectives on the Future of Behavior Change. Stanford Captology Media, Stanford.

Jariyasunant, J., et al., 2012. The Quantified Traveler: changing transport behavior with personalized travel data feedback. Transport. Res.-D 2 (2), 107-123. http://dx.doi. org/10.1068/a201285.

Jariyasunant, J., et al., 2015. Quantified traveler: travel feedback meets the cloud to change behavior. J. Intell. Transp. Syst. Technol. Plann. Oper. 19 (2), 109-124. http://dx.doi.org/10.1080/15472450.2013.856714.

Klecha, L., Gianni, F., 2017. Designing for Sustainable Urban Mobility Behaviour: A Systematic Review of the Literature. In: Citizen, Territory and Technologies: Smart Learning Contexts and Practices: Proceedings of the 2nd International Conference on Smart Learning Ecosystems and Regional Development - University of Aveiro, Portugal, 22-23, pp. 137-149. http://dx.doi.org/10.1007/978-3-319-61322-2_14.

Klein, M., Mogles, N., van Wissen, A., 2014. Intelligent mobile support for therapy adherence and behavior change. Elsevier Inc.. J. Biomed. Inform 51, 137-151. http:// dx.doi.org/10.1016/j.jbi.2014.05.005.

Kraft, P., Yardley, L., 2009. Current issues and new directions in Psychology and Health : What is the future of digital interventions for health behaviour change? Psychol. Health 24 (6), 615-618. http://dx.doi.org/10.1080/08870440903068581.

Litman, T., 2010. Quantifying the benefits of nonmotorized transportation for achieving mobility management objectives by. Transp. Res. Rec. 134-140.

Martiskainen, M., Coburn, J., 2011. The role of information and communication technologies (ICTs) in household energy consumption-prospects for the UK. Energy Effi. 4 (2), 209-221. http://dx.doi.org/10.1007/s12053-010-9094-2.

McKay, F.H., et al., 2016. Evaluating mobile phone applications for health behaviour change: a systematic review. J. Telemed. Telecare 1-9. http://dx.doi.org/10.1177/ $1357633 X 16673538$.

Meloni, I., Sanjust di Teulada, B., Spissu, E., 2017. Lessons learned from a personalize travel planning (PTP) research program to reduce car dependence. Transportation 44 (4), 853-870. http://dx.doi.org/10.1007/s11116-016-9681-y.

Moher, D., et al., 2009. Preferred reporting items for systematic reviews and meta-analyses: the (PRISMA) statement. Res. Meth. Report. 1-8. http://dx.doi.org/10.1136/ bmj.b2535.

Nilsson, L.J., et al., 2013. I ljuset av framtiden: Styrning mot nollutsläpp år 2050. LETS2050. Lunds Universitet.

Oinas-kukkonen, H., 2010. Behavior Change Support Systems: A Research Model and Agenda. Proceedings In: Persuasive Technology: 5th International Conference, PERSUASIVE 2010, Copenhagen, Denmark, June 7-10, pp. 4-14. http://dx.doi.org/ 10.1007/978-3-642-13226-1.

Oinas-kukkonen, H., Harjumaa, M., 2009. Persuasive systems design : key issues, process model, and system features. Commun. Assoc. Inform. Syst. 24 (28), 485-500.

Parvaneh, Z., Arentze, T., Timmermans, H., 2014. A stated adaptation approach to assess changes in individuals' activity-travel behavior in presence of personalized travel information. Elsevier B.V.. Transp. Res. Proc. 3 (July), 21-30. http://dx.doi.org/10. 1016/j.trpro.2014.10.087.

Pew Research Center Smartphone Ownership and Internet Usage Continues to Climb in Emerging Economies - But advanced economies still have higher rates of technology use Available at: http://www.pewglobal.org/2016/02/22/smartphone-ownershipand-internet-usage-continues-to-climb-in-emerging-economies/2016 Accessed: 13 December 2017.

Ploderer, B., et al., 2014. Social interaction and reflection for behaviour change. Pers. Ubiquit. Comput. 18 (7), 1667-1676. http://dx.doi.org/10.1007/s00779-014 0779-y.

Poslad, S., et al., 2015. Using a smart city iot to incentivise and target shifts in mobility behaviour-is it a piece of pie? Sensors 15 (6), 13069-13096. http://dx.doi.org/10. 3390/s150613069.

Potter, W.J., Levine-Donnerstein, D., 1999. Rethinking validity and reliability in content analysis. J. Appl. Commun. Res. 27, 258-284.

Prochaska, J.O., DiClemente, C.C., 1982. Transtheoretical therapy: Toward a more integrative model of change. Psychother.: Theor. Res. Pract. 19 (3), 276-288. http:// dx.doi.org/10.1037/h0088437.

Pronello, C., Simão, J.P.R.V., Rappazzo, V., 2017. The effects of the multimodal real time information systems on the travel behaviour. Transp. Res. Procedia 25, 2681-2693. http://dx.doi.org/10.1016/j.trpro.2017.05.172.

Robinson, L., 2009. A summery of Diffusion of Innovations. Changeology.

Rogers, E.M., 1995. Diffusion of innovations. 3rd editio, Macmillian Publishing Co. 3rd editio. London: Collier Macmillian Publishers. doi: citeulike-article-id:126680.

Seaborn, K., Fels, D.I., 2015. Gamification in theory and action: a survey. Int. J. Human Comput. Stud. 74, 14-31. http://dx.doi.org/10.1016/j.ijhcs.2014.09.006.

Semanjski, I., et al., 2016. Policy 2.0 platform for mobile sensing and incentivized targeted shifts in mobility behavior. Sensors (Switzerland) 16 (7). http://dx.doi.org/10. 3390/s16071035.

Semanjski, I., Gautama, S., 2016. Crowdsourcing mobility insights - reflection of attitude based segments on high resolution mobility behaviour data. Elsevier Ltd. Transp. Res. Part C: Emerg. Technol. 71, 434-446. http://dx.doi.org/10.1016/j.trc.2016.08. 016.

Sullivan, R.K., et al, 2016. Smartphone apps for measuring human health and climate change co-benefits: a comparison and quality rating of available apps. JMIR mHealth uHealth 4 (4), e135. http://dx.doi.org/10.2196/mhealth.5931.

Sunio, V., Schmöcker, J.-D., 2017. Can we promote sustainable travel behavior through mobile apps? Evaluation and review of evidence. Int. J. Sustain. Transport. 11 (8), 553-566. http://dx.doi.org/10.1080/15568318.2017.1300716.

Sweden Energy Agency, 2015. Energy Situation 2015. Available at: https://www energimyndigheten.se/contentassets/50a0c7046ce54aa88e0151796950ba0a/ energilaget-2015_webb.pdf.

Tang, J., et al., 2015. How can weight-loss app designers' best engage and support users? A qualitative investigation. Brit. J. Health Psychol. 20 (1), 151-171. http://dx.doi. org/10.1111/bjhp.12114.

Webb, T.L., et al., 2010. Using the Internet to promote health behavior change: a systematic review and meta-analysis of the impact of theoretical basis, use of behavior change techniques, and mode of delivery on efficacy. J. Med. Internet Res. 12 (1). http://dx.doi.org/10.2196/jmir.1376.

Wee, B. Van, Banister, D., 2016. How to write a literature review paper? Transp. Rev. 36 (2), 278-288. http://dx.doi.org/10.1080/01441647.2015.1065456.

Wells, S., et al., 2014. Towards an applied gamification model for tracking, managing, \& encouraging sustainable travel behaviours. ICST Trans. Ambient Syst. 14 (4), 1-9. 